\title{
O Papel Da União Africana Na Estabilização Do Burundi
}

\section{Anselmo Otavio e Nilton Cesar Cardoso}

Resumo: Este artigo analisa a atuação da União Africana (UA) em sua primeira missão de paz no continente, realizada no Burundi. Defendemos a hipótese de que sua eficácia está relacionada à estrutura adotada pela entidade, ou seja à transformação da Organização da Unidade Africana para UA, e seu impacto no âmbito securitário. Ademais, buscamos demonstrar que a nova união garantiu uma melhor dinamização na resolução do conflito no Burundi.

Palavras-chave: Organização da Unidade Africana; União Africana; Resolução de Conflitos; Burundi.

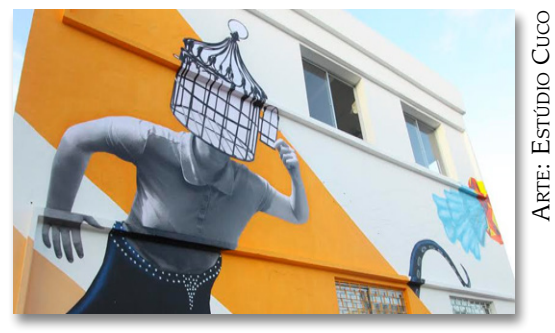

\section{The role of the African Union on the stabilization of Burundi}

\author{
Anselmo Отаvio \\ Doutorando e Mestre \\ em Estudos Estratégicos \\ Internacionais / PGEEI - \\ UFRGS e Bacharel em Relações \\ Internacionais pela UNESP- \\ Marília. anselmo_otavio@ \\ yahoo.com.br
}

\section{Nilton Cesar Cardoso}

Mestrando em Estudos Estratégicos Internacionais / PGEEI -UFRGS e Bacharel em Relações Internacionais pela UFRGS. nilton-id@hotmail.com
Abstract: This article analyzes the performance of the African Union (AU) in its first ever peace-keeping mission undertaken in Burundi. We support the hypothesis that its efficacy was related to the structure adopted by the organization, that is, its transformation from Organization of African Unity to AU and its impact on the security context. Besides, we seek to demonstrate that the new union ensured better energy in the resolution of the conflict in Burundi.

Keywords: Organization of Africa Unity; African Union; Conflict Resolution

RECEBIDO EM 16-07-2014

APROVADO EM $27-02-2015$ 


\section{INTRODUÇÃO}

A busca pela pacificação pode ser considerada como um dos principais desafios encontrados pelos países africanos no imediato pós-independência. Em certa medida, romper com guerras civis e garantir a estabilização continental se tornou uma das principais preocupações das lideranças africanas. Reflexo deste interesse pode ser encontrado na transformação da Organização da Unidade Africana (OUA) em União Africana (UA), evento que, em linhas gerais, não representou somente uma alteração nominal, mas, fundamentalmente, simbolizou a mudança de paradigmas acerca do conceito de segurança e como essa pode ser assegurada.

Surgida no pós-Segunda Guerra Mundial e fruto da cúpula de chefes de Estados africanos realizada em 1963, em Addis Abeba, Etiópia, a então OUA representava a consubstanciação dos anseios pan-africanistas de promoção da autodeterminação dos povos, do respeito à soberania dos Estados e da aclamação pela liberdade das colônias na África. Três dentre diversos eventos simbolizaram, por um lado, o declínio dos impérios europeus na África e, por outro, a reação africana a tal desintegração: a ampla participação dessa organização na intensificação dos processos de independência das colônias existentes no continente, o apoio dado aos movimentos de libertação nacional e a luta contra o regime do apartheid na África do Sul.

Diferentemente da OUA, a UA é a expressão, nos âmbitos político e securitário, da adequação da África ao mundo pós-Guerra Fria. Mesmo havendo a manutenção de pontos anteriormente valorizados pela OUA, como a busca pelo aumento da integração, da unidade e da solidariedade entre os Estados-membros, o respeito à soberania, à integridade territorial e à independência dos Estados africanos, é perceptível a ascensão de outros objetivos na UA, tais como a valorização da democracia, a good governance, com destaque para a resolução de conflitos por meios pacíficos e o direito desta organização de intervir em situações relacionadas a crimes de guerra, genocídios e crimes contra a humanidade.

Em síntese, enquanto a OUA trazia como principal objetivo romper com a dominação europeia no continente africano, a UA priorizava as questões internas dos Estados-membros, voltando-se 
à estabilização do continente por meios pacíficos, ao avanço da democracia e dos direitos humanos e, principalmente, ao direito de intervir em situações relacionadas a crimes de guerra, genocídios e crimes contra a humanidade. O reflexo dessa adaptação pode ser encontrado na estrutura adotada pela UA em 2002, que lhe confere a responsabilidade primária pela manutenção da paz e segurança do continente via trabalho em conjunto com as Regional Economic Community (RECs) africanas e em coordenação com a ONU.

Nesse sentido, o presente artigo traz como objetivo analisar a transformação da OUA para UA e seu impacto no âmbito securitário. Para isso, buscaremos compreender a atuação da União Africana em sua primeira missão de paz realizada no continente, no caso, a African Union Mission in Burundi (AMIB) e, assim, defender a hipótese de que a eficácia conquistada nesta missão se encontra relacionada à estrutura que passou a ser adotada pela organização, estrutura esta que garantiu a melhor dinamização na resolução do conflito no Burundi.

\section{PRIORIZANDO A LIBERTAÇÃO NACIONAL: A CRIAÇÃO DA OUA E SEU IMPACTO NA SEGURANÇA REGIONAL}

O fim da Segunda Guerra Mundial apresentava ao mundo uma Europa destruída. Tanto os países derrotados, como Itália e Alemanha, quanto os vitoriosos, como a Inglaterra e França, entravam na segunda metade do século XX enfraquecidos e em declínio (KENNEDY, 1989). De modo geral, o surgimento do mundo dividido entre Estados Unidos (EUA) e União Soviética (URSS), somado à falta de capacidade por parte das grandes potências europeias em se manterem fortalecidas no pós-Segunda Guerra Mundial (HOBSBAWM, 1995), tornavam-se fatores importantes no processo de desintegração dos antigos impérios europeus no continente asiático e, sobretudo, na África.

Paralelamente a esta conjuntura externa favorável aos processos de independência, o continente africano encontrava-se diante do fortalecimento do chamado pan-africanismo, semelhante ao movimento surgido no continente americano entre os séculos XVIII 
e XIX. Inicialmente lutando pelo fim da escravidão, o que o tornou cada vez mais relevante na África, o pan-africanismo passou a defender pontos como a revogação de leis racistas e discriminatórias, a abolição do trabalho forçado, o direito ao voto e o ativismo na emancipação e na total independência das colônias existentes no continente. Gradualmente essas posições tornaram-se preponderantes nos movimentos de libertação surgidos no continente (CHANAIWA; KODJO, 2010).

Em certa medida, o êxito das reivindicações ocorreu durante a primeira metade da década de 1960, período em que a África passou de 26 para 33 países independentes. Entretanto, com o advento da OUA, as lideranças africanas encontraram um importante meio voltado ao combate do jugo colonial e do racismo, à promoção do desenvolvimento econômico e à estabilização dos Estados membros recém-independentes (FRANCIS, 2006; AFRICAN UNION, 1963).

A OUA refletia o anseio pan-africanista de uma estrutura fiel à luta contra qualquer forma de dominação herdada do imperialismo europeu. Estruturou-se na Assembly of Heads of State and Government, Council of Ministers, General Secretariat, e Commission of Mediation, Conciliation and Arbitration, art. VII da OAU Charter (AFRICAN UNION, 1963, p. 5), entidade em que se destacam as lutas pela autodeterminação dos povos, os ideais de liberdade, justiça e igualdade, o respeito aos direitos humanos e a preservação da soberania dos Estados.

No âmbito político, tal característica refletiu-se no apoio dado aos processos de independência do continente. A OUA emitiu solicitações para que os países-membros treinassem militarmente os movimentos de libertação do continente por meio do Comitê Africano de Libertação, composto por países como a Argélia, Egito, Etiópia, Guiné, Nigéria, Uganda, Senegal, Tanzânia, organização que se destacou ao propor auxílio financeiro a estes movimentos (CHANAIWA; KODJO, 2010). Reflexo desta atuação pode ser encontrado no apoio aos movimentos como o Zimbabwe African National Union (ZANU) e o Zimbabwe African People's Union (ZAPU) - ambos voltados à independência da Rodésia do Sul, país que se tornaria independente em 1980, adotando o nome de Zimbábue 
- e o South West Africa People's Organization (SWAPO) - movimento que lutava pela independência da Namíbia, conquistada em 1990 (CHANAIWA, 2010).

No âmbito econômico, romper com qualquer forma de dominação do imperialismo europeu no continente significava romper com a relação de dependência e desequilíbrio existente entre os países africanos - cujas exportações eram marcadas pelo predomínio dos produtos primários e importações de bens manufaturados - e os países ocidentais, principais consumidores de tais produtos e exportadores de bens industrializados (CHINWEIZU, 2010). A OUA pautou-se no Lagos Plan Action (LPA), de 1980, voltado para questões relacionadas à agricultura, indústria, recursos naturais, ciência e tecnologia, transportes e comunicações, comércio e finanças, meio-ambiente, entre outros (ORGANISATION OF AFRICAN UNITY, 1981). Não obteve o mesmo êxito no âmbito político, visto que ao longo da década de 1980 e dos anos iniciais de 1990, a pobreza excessiva e as baixas taxas de crescimento econômico foram reinantes no continente africano (FUNKE; NSOULI, 2003).

Semelhante ao fracasso na esfera econômica, a OUA também foi falha no campo securitário. Em certa medida, a incapacidade desta organização no que tange a prevenção e resolução de conflitos encontra-se atrelada principalmente a três motivos. O primeiro, diz respeito à própria estrutura institucional e funcional da OUA, na medida em que o seu principal órgão, a Assembly of Heads of State and Government, só podia deliberar sobre uma intervenção militar se convidado pelas partes em conflito e se houvesse consenso entre seus membros (MURITHI, 2008). O segundo motivo refere-se à existência da chamada guerra proxy (guerra por procuração). Se por um lado a guerra foi preponderante na África a partir da década de 1970, quando se encontrava atrelada a um envolvimento tanto dos Estados Unidos quanto da União Soviética no continente africano, por outro, o surgimento deste tipo de guerra impôs limites à atuação da OUA, que não foi capaz de romper com a instabilidade gerada pela intervenção das duas principais potências daquele período. Por fim, a última motivação do fracasso da OUA diz respeito ao não pagamento das cotas de manutenção da organização por parte dos Estados-membros, fato que alijou 
a OUA de sua principal fonte de financiamento, transformando a organização em uma tribuna política e em uma ferramenta de representação externa do continente africano (VISENTINI, 2010).

De fato, a OUA mediou com sucesso as disputas de fronteiras entre Marrocos e Argélia (1963), Somália e Quênia (1964) e entre Líbia e Chade (1977), eventos que demonstravam uma das principais características da organização, qual seja a de atuar enviando pequenas missões de observadores voltadas à resolução de disputas de fronteiras. Assim, ao longo de todo o período da Guerra Fria, a organização enviou apenas uma força militar para intervir na guerra civil no Chade em 1981 (OAU Neutral Force in Chad), iniciada em 1960. A iniciativa foi tomada a partir de pressões advindas de países externos ao continente, principalmente da França.

Em síntese, a OUA demonstrou ser um órgão mais deliberativo que decisório, no contexto de uma estrutura simples para alcançar a estabilidade continental e romper com as diversas guerras civis surgidas no Sudão, na Somália, no Burundi, em Ruanda e na República Democrática do Congo, entre outros países (ESCOSTEGUY, 2011). Se por um lado, a OUA foi eficaz na intensificação dos processos de independência surgidos na África, por outro, não obteve o mesmo êxito em alcançar a estabilidade continental, fator fundamental para a sua transformação em União Africana em 2002.

\section{PRIORIZANDO A SEGURANÇA REGIONAL: A TRANSFOR- MAÇÃO DA OUA EM UA}

Impulsionado pelo fim da Guerra Fria, o sistema ONU inaugurou uma nova fase no campo securitário. Em certa medida, com o fim da disputa entre Estados Unidos e União Soviética - que possibilitou o maior grau de consenso entre os cinco membros permanentes (China, Estados Unidos, França, Inglaterra e Rússia) no Conselho de Segurança das Nações Unidas (CSONU) - e com a própria transformação na concepção do que seria uma ameaça à Segurança Internacional (Cap. VII da Carta da ONU), houve o aumento da complexidade das missões de paz e de suas responsabilidades (MINGST, 2009), visto que os conflitos armados intra-estado de 
grande escala, especialmente as guerras civis, passaram também a ser consideradas ameaças à paz e a Segurança Internacional.

Duas características refletiam este novo momento das operações de manutenção de paz da ONU. A primeira diz respeito à composição dos contingentes que passaram a fazer parte das missões de paz: se durante a primeira geração de missões de paz (1948-1987) eram compostos somente por militares, após a Guerra Fria passaram a contar com a participação de civis. Já a segunda característica refere-se à valorização de pontos, como o aumento da qualidade de vida e a melhoria na condição de dignidade da pessoa humana, que passaram cada vez mais a ser vistos como importantes para a consolidação da pacificação e a prevenção de novos conflitos (GODOI, 2010).

Em linhas gerais, tais características, que simbolizavam a transformação no Sistema ONU, encontravam-se em consonância com dois importantes relatórios surgidos na primeira metade da década de 1990. Idealizado pelo então Secretário-Geral da ONU, BoutrosBoutros Ghali, e intitulado "An Agenda for Peace: preventive diplomacy, peacemaking and peacekeeping", o primeiro relatório em destaque reconhecia as mudanças de natureza das próprias operações realizadas pela organização, as quais eram mais limitadas à tradicional manutenção da paz (UNITED NATIONS, 1992). Surgido em 1992, este documento previa a necessidade de um desvio do principio anteriormente aceito de consentimento das partes e a imposição da paz (peace enforcement) seria, então, componente das novas missões para um cessar-fogo, tomando-se medidas coercivas contra quem o violasse (DORN; PAUK, 2012).

Já o segundo, este desenvolvido três anos após a criação do relatório anteriormente indicado e conhecido como "Supplement to An Agenda for Peace", voltava-se ao desenvolvimento de instrumentos de controle e resolução de conflitos inter e intra-Estados de acordo com seu objetivo e forma de atuação. Em síntese, se o primeiro relatório conceituava acerca dos tipos de missões de paz, este segundo relatório institucionalizou a chamada "preventive diplomacy" - ações voltadas à contenção de conflitos através da diplomacia, as missões de "peacemaking" - voltadas à pacificação através da busca em trazer as partes conflitantes para o diálogo, 
as missões de "peace-keeping" - ativadas após o consentimento das partes conflitantes e caracterizadas pela presença de contingentes da ONU, e as missões de "peace-building" - voltadas ao fortalecimento de estruturas importantes para a solidificação da paz (BOUTROS-GHALI, 1992).

Embora havendo a transformação no Sistema ONU, tornando as missões de paz cada vez mais complexas, esse acontecimento não necessariamente simbolizou o desejo por parte das potências ocidentais em serem mais atuantes em tais missões, principalmente naquelas voltadas ao continente africano. De fato, em um cenário não mais dividido entre Estados Unidos e União Soviética, fator que diminuía o caráter estratégico da África para as potências da época (AKOKPARI, 2001), somado aos incidentes ocorridos na Somália (1993) e em Ruanda (1994), o que se viu foi o desinteresse e a relutância por parte da grande maioria dos países ocidentais em atuar nas missões de paz surgidas no continente. É imbuído neste contexto de desinteresse de um lado e na necessidade em pacificar a África de outro, que algumas lideranças africanas viram a necessidade da OUA passar por transformações, no sentido de ampliar o seu escopo institucional, adequando-o à nova conjuntura internacional e respondendo aos desafios existentes no continente.

De modo geral, é possível indicar que uma das primeiras iniciativas voltada à transformação da OUA em um importante instrumento de pacificação do continente africano se deu com o surgimento, em 1989, do chamado Movimento Kampala (Kampala Movement) idealizado por Olusegum Obasanjo, proeminente político nigeriano que, futuramente, se tornaria em um dos principais arquitetos da estrutura adotada pela UA, que indicava ser necessária a transformação da OUA e a priorização dos desafios securitários existentes no continente africano. O intuito era impulsionar a reforma política e a cooperação regional com vista a melhorar o potencial da África na promoção da estabilidade e do desenvolvimento econômico (DENG; ZARTMAN, 2002).

Além de trazer ao centro das discussões o conceito de segurança humana e sua integração às normas e diretrizes da OUA, uma das principais contribuições do Movimento Kampala diz respeito à 
Conferência sobre a Segurança, Estabilidade, Desenvolvimento e Cooperação na África (CSSDCA, do inglês Conference on Security, Stability, Development, and Cooperation in Africa), iniciativa que propunha o desenvolvimento de um mecanismo de manutenção da paz continental, a prevenção de conflitos e a promoção de autossuficiência militar na África, a criação de um African Peace Council of Elder Statesmen, pautado na mediação de conflitos e na drástica redução dos gastos militares no continente (ADEBAJO, 2007, p. 224).

Enviada em julho de 1991 à Assembleia da OUA para ser discutida e incorporada oficialmente à estrutura, mesmo recebendo o apoio de proeminentes lideres africanos como Nelson Mandela e do Secretário-Geral da OUA à época, Salim Ahmed Salim, tal proposta foi rejeitada pela OUA, uma vez que diversos países-membros foram contrários à iniciativa, tais como o Quênia de Daniel Arap Moi, a Líbia do Coronel Muammar Qaddafi e o Sudão de Omar al-Bashir (TIEKU, 2004). No entanto, a rejeição da proposta não eliminou a importância do movimento. Em verdade sua existência deixou como legado a crença de que a estabilidade e pacificação da África estariam atreladas à reforma na estrutura da OUA, iniciada em 1999, durante a Cúpula Extraordinária da OUA, realizada em Sirte, Líbia.

Polarizada, de um lado, pela Nigéria e África do Sul, ambas favoráveis a retomada da Declaração da CSSDCA, e de outro lado a Líbia, cujo projeto de reforma da OUA girava em torno do projeto levantado pelo grupo de Casablanca acerca da viabilidade de transformar o continente africano no chamado "Estados Unidos da África" (TIEKU, 2004), a reunião ocorrida em Sirte iniciou um longo processo que culminou em 2002, na Cúpula de Durban, África do Sul, com a substituição da OUA por UA, marcando pelo predomínio da Declaração da CSSDCA nessa transição.

De fato, além de estar diluída na estrutura da UA com os nomes de Economic, Social and Cultural Council (ECOSOCC) e no Council of Elders (ADEBAJO, 2007), os pontos valorizados pela CSSDCA podem ser encontrados no Constitutive Act of the African Union (CAAU), documento fruto da Cimeira de Lomé, ocorrida em 2000 no Togo. Em linhas gerais, mesmo havendo a manutenção por 
parte da UA de alguns pontos contidos na Carta da OUA, configurou-se a busca pelo aumento da integração e da solidariedade entre os Estados, preservando-se o princípio de não ingerência nos assuntos internos dos demais países membros. Exemplificando, o Artigo $4^{\circ}$, letra $h$, do CAAU, confere "o direito de a união intervir num Estado membro, em conformidade com a decisão da Conferência, em situações graves como crimes de guerra, genocídios e crimes contra a humanidade" (AFRICAN UNION, 2000, p. 7, tradução nossa), o que rompe definitivamente com um dos princípios fundamentais da OUA.

Nesse sentido, a UA não só tem a responsabilidade de intervir sem o consentimento das partes para proteger as populações vulneráveis e restaurar a paz e estabilidade, mas também prevenir que essas situações ocorrem. Ademais, a UA concedeu o direito da União de intervir num Estado membro, utilizando meios coercivos quando necessário, mesmo sem consenso no Conselho de Paz e Segurança (CPS) da UA. Desse modo, a UA deixou de lado o principio de não intervenção que regia a OUA e passou a adotar o principio da não indiferença. Além disso, outra importante mudança da UA em relação a sua predecessora foi à institucionalização do conceito de segurança humana, englobando o bem-estar econômico, político e social dos cidadãos (FRANCIS, 2006; MURITHI, 2008).

Expondo acerca no Ato Constitutivo da União Africana, Francis (2006) considera que este ato encontra-se baseado em três princípios normativos fundamentais. O primeiro diz respeito ao desenvolvimento e fortalecimento da posição do continente na diplomacia econômica e comercial internacional. O segundo é desenvolver uma estrutura de segurança continental coletiva baseada na interdependência mútua e relações interestatais pacíficas. E o terceiro refere-se à intenção de desenvolver uma colaboração mais estreita com as diversas comunidades econômicas sub-regionais (RECs) e sistemas de defesa e segurança na persecução dos objetivos de desenvolvimento continental, paz e segurança.

Referente a este último principio, antes mesmo da transformação da OUA para UA, é possível encontrarmos episódios em 
que as RECs atuaram no campo de paz e segurança. Um primeiro exemplo pode ser encontrado na África Ocidental, onde a Economic Community of West Africa (ECOWAS), através da Economic Community of West African States Monitoring Group (ECOMOG), interveio na guerra civil Liberiana, em 1990, em coordenação com a OUA e a ONU e liderada pela Nigéria. Além disso, com a eclosão da guerra civil na vizinha Serra Leoa, em março de 1991, a atuação da ECOMOG foi expandida para este país. Em 1998 e 2002 também atuou na Guiné Bissau e na Costa do Marfim respectivamente (FRANCIS, 2006).

Além do exemplo anterior, pode-se destacar a intervenção militar promovida pela Southern African Development Community (SADC) no Reino do Lesoto, sob a liderança da África do Sul e da Botsuana. Buscando restabelecer a paz no país após a crise surgida com a não aceitação por parte da oposição da vitória do Lesotho Congress for Democracy (LCD) nas eleições de 1998 (SOUTHALL, 2003), tal intervenção pode ser considerada bem sucedida, visto que garantiu tanto a estabilidade necessária ao país, fator importante para a criação de um cenário propício para as negociações entre o LCD e a oposição (KENT; MALAN, 2003), como também foi fundamental no incentivo a todas as partes em aceitarem a revisão do código eleitoral do país, no qual foi introduzido o Mixed Member Proportional (MMP), sistema que garantia à oposição representatividade no Legislativo, e que, durante as eleições de 2002, demonstraria ser eficaz.

Além dos pontos encontrados na análise de Francis (2006), outra característica que também faz parte dessa tendência encontrada na UA relativa às questões securitárias existentes no continente diz respeito ao Protocolo para o Estabelecimento do Conselho de Paz e Segurança (CPS) da UA também criado em 2002, na Cúpula de Durban.

Estabelecido como principal órgão decisório da UA para as questões referentes à segurança e guiado pelos princípios contidos no Ato Constitutivo da União Africana, na Carta das Nações Unidas, na Declaração Universal dos Direitos Humanos (artigo $4^{\circ}$ ), os objetivos principais do CPS (artigo $3^{\circ}$ ) consistem em promover 
a paz, a segurança e estabilidade no continente; a antecipação e prevenção do conflito; a promoção e execução de atividades de consolidação da paz e reconstrução pós-conflito; a coordenação e harmonização dos esforços em nível continental para a prevenção e combate ao terrorismo internacional; o desenvolvimento de uma política de defesa coletiva da União Africana; e a promoção e encorajamento de práticas democráticas, boa governança, estado de direito e proteção dos direitos humanos e liberdades fundamentais (AFRICAN UNION, 2002, p. 5-6).

O CPS é composto por quinze membros, dez eleitos por um período de dois anos e cinco eleitos por um período de três anos, de modo a assegurar a continuidade. Esse conselho possui poderes comparáveis ao CSNU no nível continental, porém não existe veto ou qualquer distinção entre os poderes de uns e outros e, ao contrário dos membros não permanentes do Conselho de Segurança das Nações Unidas, existe para todos a possibilidade de reeleições sucessivas (AFRICAN UNION, 2002; ESCOSTEGUY, 2011). Além disso, vale destacar que um dos componentes essenciais do Conselho é o estabelecimento de um Sistema Continental de Alerta Antecipado (Continental Early Warning System) e a criação de Fundo para Paz, um Conselho de Eruditos (Painel of Wise), uma Força Africana de Intervenção (The African Standby Force) e uma Comissão Militar (Military Staff Comittee) (VISENTINI, 2010, p. 206).

Em síntese, ao compararmos a OUA com a UA, torna-se claro que os desafios securitários passaram a ser cada vez mais relevantes para a principal organização existente no continente. Em verdade, se durante a vigência da OUA procurava-se a segurança do continente por meio da institucionalização e legitimação do Estado na África, bem como a valorização dos princípios de soberania e integridade territorial, com a transição para a UA o que se viu foi à crença na necessidade de se proteger primariamente a pessoa humana, demonstrando assim a percepção mais ampla do significado de segurança. Um exemplo que demonstra, na prática, o uso desses novos dispositivos institucionalizados na UA pode ser encontrado no processo de pacificação do Burundi. 


\section{A UNIÃO AFRICANA E O PROCESSO DE PACIFICAÇÃo DO BURUNDI}

O cenário político da década de 1990 no Burundi remete à histórica disputa, muitas vezes com resultados trágicos, entre hutus e tutsi pelo poder. Reflexo disso, pode ser encontrado no cenário político do país, que embora complexo, uma vez que era marcado pela grande diversidade de partidos, denunciava uma clara polarização entre favoráveis a uma etnia e os adeptos da outra. Referente aos hutus, o bloco era composto por partidos como o Conseil National pour la Défense de la Démocratie (CNDD), o Parti Populaire (PP), o Rassemblement du Peuple Burundais (RPB), o Parti pour la Liberation du Peuple Hutu (PALIPEHUTU), a Front pour la Libération Nationale (FROLINA) e, principalmente, a Front pour la Démocratie au Burundi (FRODEBU), este representado por Melchior Ndadaye, candidato que disputaria e venceria a eleição de 1993 para a presidência do país (MITI, 2012).

Diferentemente dos hutus, e composto por um maior número de partidos, o grupo dos tutsis enquadrava o Parti pour le Redressement National (PARENA), o Parti pour la Réconciliation du Peuple (PRP), O Parti Social Démocrate (PSD), a Alliance Burundo-Africaine pour le Salut (ABASA), a Rassemblement pour la Démocratie, le Développement Economique et Social (RADDES), a Alliance des Vaillants (AV-INTWARI), a Alliance Nationale pour le Droit et le Developpement Economique (ANADDE), e com destaque a Union pour le Progrès National (UPRONA), cujo maior expoente, Pierre Buyoya, já havia chegado ao poder em 1987, após um golpe militar, e, seria derrotado na eleição de 1993 pelo candidato da FRODEBU (SOUTHALL, 2006).

O caráter pacífico do processo eleitoral de 1993 e a vitória da FRODEBU sobre a UPRONA - importante marco na história política do país, visto que pela primeira vez um membro hutu chegava ao poder no Burundi (BOSHOFF; VREY; RAUTENBACH, 2010) - eram acontecimentos que, em certa medida, geravam expectativas com relação à possibilidade em acabar com os constantes atritos entre as duas etnias. No entanto, o assassinato de Ndadaye seguido a uma onda de protestos e ataques por parte dos hutus contra os 
tutsis, novamente tornou o país palco de um cenário político instável (MITI, 2012).

Inicialmente, a busca em restabelecer a paz foi marcada pela tentativa da FRODEBU e da UPRONA em criarem um governo de coalizão, em que o partido representante dos hutus ficaria com a presidência do país e o representante tutsi assumiria a cadeira de primeiro-ministro. Em paralelo a isso, países como Tanzânia e Uganda, com a participação de Julius Nyerere, símbolo de luta pela independência da Tanzânia e de criação da OUA, buscavam convencer os militares a aceitarem uma missão de peacekeeping (BOSHOFF; VREY; RAUTENBACH, 2010).

Todavia, a complexidade deste cenário tornou-se visível uma vez que partidos contrários a tal resolução, no caso, o Conseil National pour la Défense de la Démocratie (CNDD), Parti pour la Liberation du Peuple Hutu (PALIPEHUTU) e Front pour la Libération Nationale (FROLINA), todos representantes da etnia hutu, passaram a realizar ataques a civis (BOSHOFF; VREY; RAUTENBACH, 2010).

O fracasso em romper com tal cenário tornava o país propício a um golpe militar, fato consumado em julho 1996 por Buyoya, que anteriormente havia perdido as eleições para Ndadaye. Discutindo acerca deste acontecimento, Miti (2012) expõe acerca das divergências entre os países africanos, que viam a ascensão da UPRONA como um duro golpe para a estabilidade e a democracia do país. Segundo o autor,

A cúpula regional [...] foi convocada às pressas para lidar com o golpe de 1996, no Burundi. A cimeira, que veio a ser conhecida como a Regional Initiative for Burundi, impôs sanções econômicas contra o novo regime em Bujumbura e apelou ao novo governo para restaurar a Assembleia Nacional, restabelecer os partidos políticos e começar imediatamente negociações com todas as partes no conflito tanto dentro como fora do país. As sanções, no entanto, encontraram forte oposição por parte da União Europeia e dos Estados Unidos, que acreditavam firmemente no trabalho com os chamados líderes moderados. Buyoya, o novo presidente, foi considerado pela UE e pelos EUA como um moderado e, portanto, digno de apoio. Isto minou os esforços regionais e resultou na promulgação de uma constituição interna de transição em 1998, legitimando assim o golpe e presidência de Buyoya. (MITI, 2012, p. 28, tradução nossa). 
Intitulado de Acordo de Arusha I, esta primeira tentativa de pacificação do Burundi foi marcada pelo fracasso. No entanto, passado dois anos, teve inicio o que seria conhecido como Acordo de Arusha II, marcado pela presença de representantes de partidos e grupos políticos de Uganda, Quênia, Ruanda e Tanzânia e, novamente, pela atuação de Nyerere como mediador, posto que, após sua morte em 1999, seria assumido por Nelson Mandela, já como ex-presidente da África do Sul (MITI, 2012). Em linhas gerais, discutindo acerca deste acordo, Southall (2006, p. 114, tradução nossa) destaca que o Acordo de Arusha II pautou-se na busca pela aceitação das lideranças políticas do Burundi dos seguintes pontos: 1) a transição liderada por um governo interino para culminar em eleições democráticas; 2) a criação de um Senado e alterações na composição da Assembleia Nacional existente; 3) a reforma judicial para diminuir o predomínio tutsi; 4) a reforma militar para diminuir o predomínio tutsi e facilitar a integração das forças rebeldes no exército; 5) a criação de uma Comissão de Verdade e Reconciliação; 6) uma força militar internacional para ajudar na gestão da transição; 7) a investigação independente sobre supostos crimes de genocídio.

Em certa medida a total aceitação do Acordo de Arusha II encontrou obstáculo na negativa dada por parte do CNDD e do PALIPEHUTU, e seus respectivos braços armados, Forces pour la Défense de la Démocracie (FDD) e Forces Nationales de Libération (FNL), que não eram favoráveis aos pontos anteriormente indicados (BOSHOFF; VREY; RAUTENBACH, 2010; MITI, 2012). Logo, se a UPRONA e a FRODEBU entravam em acordo no que diz respeito à participação de Buyoya e Ndayizeye, que havia se tornado sucessor de Ndadaye, o não apoio a este acordo por parte do CNDDFDD e do PALIPEHUTU-FNL mantinha o Burundi em um cenário de instabilidade. No entanto, mesmo não sendo amplamente apoiado, o Acordo de Arusha II se diferenciou do Arusha I pois seus principais objetivos foram implementados.

Inicialmente, em 2001, foi estabelecido um Governo de Transição no Burundi (TGoB, do inglês Transitional Government of Burundi) através da implementação do acordo de power-sharing (distribuição de poder) firmado em 2000. Com o objetivo de criar 
um Governo de Unidade e Conciliação Nacional, foi acordado entre as partes que no período entre 2001 a 2003 a presidência do TGoB caberia a um representante tutsi e a vice-presidência a um representante hutu e no período subsequente, 2003 a 2005, essa lógica seria invertida. Além disso, 14 dos 26 ministérios e 60\% dos assentos na Assembleia Nacional caberiam aos representantes hutus (PAPAGIANNI, 2009). Em síntese, o principal objetivo desse tipo de arranjo era incluir grupos com interesses divergentes no processo decisório do Estado e de governo (instituições políticas, burocracia e forças armadas) e, consequentemente, reduzir possibilidades de alterações bruscas e desestabilizadoras do Estado (BEKOE, 2008; WILLIAMS, 2011).

No ano de 2002, teve-se inicio a segunda fase de negociações de paz, focada na criação de acordo de cessar-fogo entre o TGoB e o Armed Political Parties and Moviments (APPMs) - assinado em outubro, em Dar-es-Salaam - e entre o TGoB e o CNDD-FDD, também assinado em 2002, porém no mês de dezembro e na cidade de Arusha (AGOAGYE, 2004; PEEN RODT, 2011). Em síntese, entre os pontos encontrados nos acordos, destacam-se sua incorporação no governo de transição e a solicitação junto a UA de uma missão de monitoramento e verificação da sua implementação.

Já em abril de 2003, quando da 91 Cúpula Ordinária do Mecanismo para a Prevenção, Gerenciamento e Resolução de Conflitos da UA, realizada em Adis Abeba, o passo seguinte para a estabilização do Burundi ocorreu através do estabelecimento da African Union Mission in Burundi (AMIB), cuja durabilidade seria inicialmente de um ano. Primeira missão de paz desenvolvida pela UA, a AMIB buscava através da estabilização política e econômica do país, da criação de um acordo de cessar-fogo, do apoio ao Desarmamento, Desmobilização e Reintegração (DDR) dos ex-combatentes, entre outros objetivos (BOSHOFF; VREY; RAUTENBACH, 2010), criar um cenário favorável à instalação de uma missão de paz da ONU voltada ao Burundi (MURITHI, 2008).

Em linhas gerais, através da participação de tropas advindas da Etiópia, de Moçambique e da África do Sul - países que foram importantes para a pacificação de grande parte do território deste país (MURITHI, 2008) - e de observadores militares provenientes 
de Burkina Faso, Gabão, Mali, Togo e Tunísia, tal objetivo foi alcançado por meio da aprovação da resolução 1545, do Conselho de Segurança da ONU, na qual foi estabelecida a United Nations Operations in Burundi (ONUB), em maio de 2004, que englobaria a AMIB (SECURITY COUNCIL, 2004). No entanto, para alcançar tal finalidade, o que se viu foi o uso da nova estrutura institucional e dos instrumentos normativos que passaram a fazer parte da UA.

A AMIB foi estabelecida com estreita colaboração da ONU, que além de oferecer apoio administrativo e logístico recebeu apoio técnico da MONUC (do inglês, United Nations Organization Mission in Democratic Republic of Congo) nas áreas de informação pública e DDR. Além disso, a AMIB se destaca por duas outras características. A primeira diz respeito à adoção do modelo de operações de paz simples, isto é, tipo de missão de paz pautado no princípio do uso mínimo da força, reservada à autodefesa, e à defesa do mandato. Já a segunda característica refere-se ao uso de contingentes compostos não apenas por militares, mas também por civis especializados em ações voltadas para o aumento da qualidade de vida e a melhoria na condição de dignidade da pessoa humana, objetivando a consolidação da paz e a prevenção de novos conflitos no país. Percebe-se aqui o caráter multidimensional da AMIB.

No que concerne à implementação dessa missão, é possível indicar a dificuldade por parte da UA em dispor dos recursos financeiros necessários à execução de todas as ações planejadas. Se no início da AMIB o orçamento para a implantação, operacionalização e sustentação por um período de 12 meses foi estimado em US\$ 110 milhões, após 14 meses a missão foi concluída com um custo total de US\$ 134 milhões, isto é, um excedente de mais de um terço do orçamento total da comissão da UA para o ano de 2003 (PEEN RODT, 2011).

De modo geral, a UA buscou suprir esta dificuldade financeira através de dois meios. O primeiro refere-se à simplificação da administração e da logística adotada pela AMIB através da adoção de memorandos de entendimento assinados entre a UA e os países contribuintes com tropas na missão. Nesses acordos, África do Sul, Moçambique e Etiópia deveriam sustentar os seus respectivos contingentes por um período de até 60 dias e aguardarem o 
reembolso por parte da comissão da UA. Entretanto, com a fraca capacidade financeira, especialmente dos dois últimos países, o que se viu foi os sul-africanos, cujo contingente era o maior da missão (1.600 dos 3.335), assumirem grande parte do ônus financeiro da operação, além de contribuírem com a maioria dos meios logísticos, inclusive combustíveis, transportes e suprimentos médicos (SANTOS, 2011).

Em paralelo à preponderância e, em certa medida, dependência da África do Sul, o outro meio encontrado pela UA para custear a AMIB se deu através da ajuda de países não africanos, como os EUA e a Grã-Bretanha, cujos financiamentos foram importantes para a implantação dos contingentes etíopes e moçambicano, respectivamente. Em síntese, ao final da missão, a África do Sul arcou com o custo de US\$ 70 milhões, a Etiópia com US\$ 34 milhões e Moçambique com US\$ 6 milhões. A União Europeia contribuiu com 25 milhões de euros - o que lhe conferiu o status de principal contribuinte externo à AMIB (SANTOS, 2011). Percebese, portanto, o alto grau de dependência financeira da UA em relação aos recursos externos para a execução das suas iniciativas no campo de paz e segurança.

Com relação à atuação e distribuição dos contingentes sul-africanos, etíopes e moçambicanos no Burundi, é possível indicar que, embora baseado na Capital do país, Bujumbura, a AMIB estabeleceu dois centros de desmobilização situados nas cidades de Muyange, na província de Bubanza, sob a responsabilidade das tropas sul-africanas, e na cidade de Buhinga, na província de Rutana (ver Mapa 1), coordenada pelas tropas etíopes. Já os contingentes provenientes de Moçambique ficaram responsáveis pela escolta de comboios humanitários e de todos os movimentos feitos pelos membros da missão e das ONG's humanitárias. A exceção coube à movimentação dos lideres dos grupos insurgentes para os locais de negociações e de acantonamento designados e a proteção pessoal aos políticos exilados em seu retorno ao país, que ficou sob a égide da unidade especial do South Africa National Defence Force (SANDF) (AGOAGYE, 2004). 
Mapa 1 - Mapa do Burundi

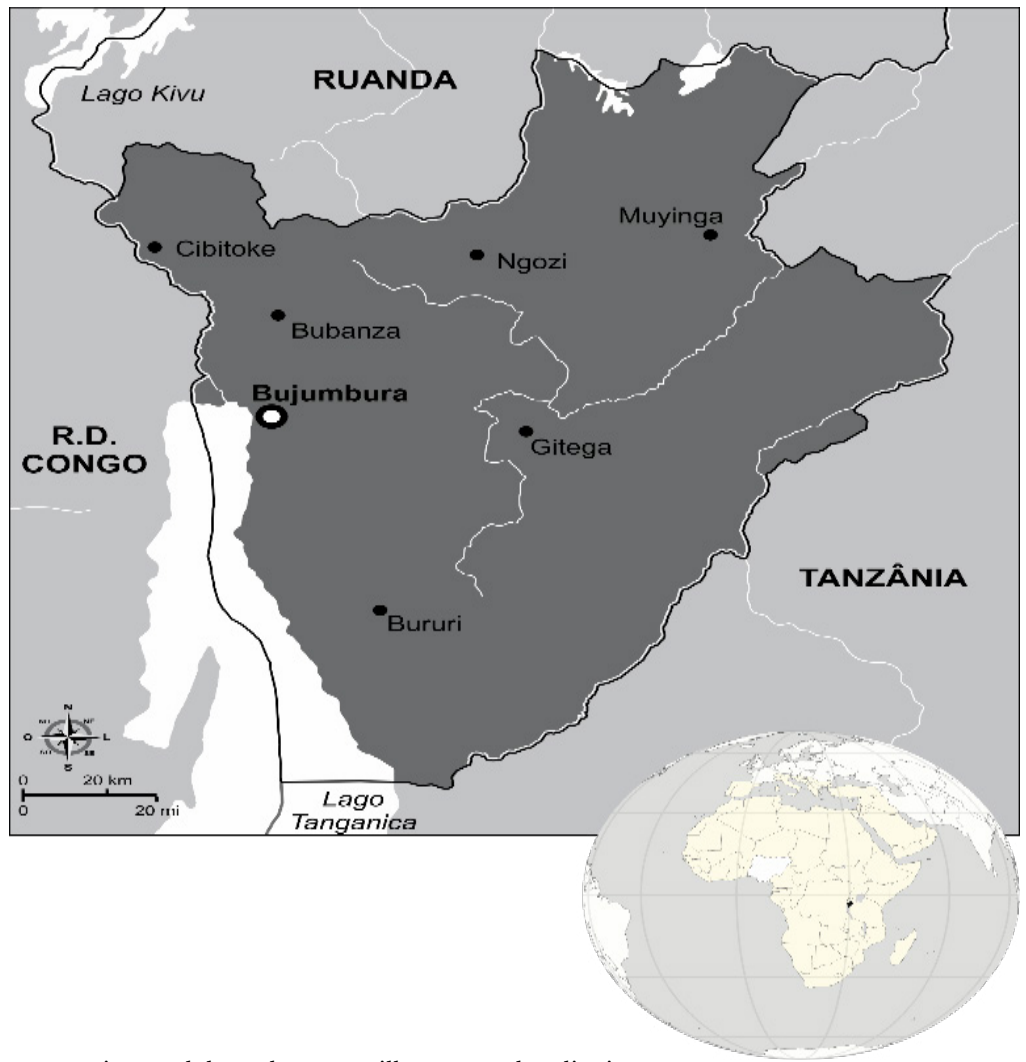

Fonte: Figura elaborada por Guilherme Z. de Oliveira.

Paralelamente às ações da AMIB, uma nova fase de negociações mediadas pelos países da região possibilitou a assinatura de um acordo de paz abrangente entre o TGoB e o grupo insurgente CNDD-FDD (liderado por Pierre Nkurunziza, em novembro de 2003, em Dar-Es-Salaam, na Tanzânia, quando da 20 Cimeira da Iniciativa Regional para a Paz no Burundi. Neste acordo, ficou decidida a incorporação ao governo de transição e, após o desarmamento dos seus combatentes, a anexação dos membros do grupo insurgente ao exército nacional. O sucesso do acordo de paz possibilitou que a estabilidade fosse atingida em grande parte do território do Burundi. Desse modo, quase a totalidade dos grupos 
beligerantes - agora partidos políticos - estavam representados nas instituições de transição (SVENSSON, 2008).

Em relação ao Desarmamento e Desmobilização e Reintegração (DDR) dos ex-combatentes, a expectativa inicial da AMIB era desarmar cerca de 20.000 combatentes, isto é, cerca de 300 por dia. Entretanto, devido às dificuldades estruturais existentes, esse projeto fracassou na medida em que a AMIB não dispunha de tropas suficientes para proteger as áreas de acantonamento. Além disso, a inabilidade da AMIB em sustentar os ex-combatentes também contribuiu para o fracasso desse projeto (PEEN RODT, 2011). A falta de meios de mobilidade tática dificultava a ação fora das áreas urbanas e a maioria das tropas não estavam treinadas para a função de proteção de civis. Ademais, os memorandos de entendimento que deveriam regular as relações entre a UA, os países contribuintes de tropas e o Burundi nunca chegaram a ser finalizados (SANTOS, 2011).

Todavia, mesmo havendo tais dificuldades, a atuação da AMIB foi importante no retorno e na ajuda aos refugiados e deslocados internos, na assistência humanitária, no fornecimento de escoltas armadas aos comboios humanitários e no auxilio à formação e implementação da uma nova força de segurança no país, a Burundi National Defense Force e a Police Force, fatores importantes na pacificação do Burundi. Em certa medida, o reflexo desta atuação pode ser encontrado não apenas em fevereiro de 2004, quando a ONU concluiu que a AMIB havia garantido as condições apropriadas para o estabelecimento de uma missão de paz no país - consubstanciada em maio de 2004 através da resolução $n^{\circ}$ 1545, do Conselho de Segurança, e intitulada de United Nations Operations in Burundi (ONUB) - mas também pelo englobamento da primeira missão de paz da UA na ONUB.

De modo geral, antes de ser substituída pela United Nations Integrated Office in Burundi (BINUB), em 2006, voltada para a assistência técnica no desenvolvimento de um plano de Reforma do Sector de Segurança (RSS), que inclui a formação da força policial e do exército nacional do Burundi, a ONUB ajudou a desarmar e desmobilizar cerca de 22.000 ex-combatentes, incluindo mais de 3.000 crianças e cerca de 500 mulheres, perto de 30 mil membros 
das milícias e em torno de 3.000 agentes adicionais do exército, que também foram desarmados e assistidos (NHLAPO, 2006).

No ano de 2005, além de ser promulgada uma nova constituição, foi realizada em julho as eleições para a Assembleia Nacional. Neste mesmo ano, em agosto, essa mesma assembleia elegeu por voto indireto o candidato do CNDD-FDD à presidência, Pierre Nkurunziza, este que seria reeleito em maio de 2010 no primeiro sufrágio direto realizado no país desde 1993 (INTERNATIONAL CRISIS GROUP, 2011; VISENTINI, 2012). Além disSo, o último grupo insurgente, a FNL, aceitou negociar e, após desarmar os seus combatentes, que foram incorporados ao exército nacional, foi registrado como partido político em 2009.

Em suma, a aceitação dos resultados das eleições de 2010 por parte dos partidos políticos, principalmente pela UPRONA e do FRODEBU, simbolizou não apenas o amadurecimento da arena política interna e o comprometimento desses com a estabilidade política do Burundi, mas também representou a vitória da UA, visto que a busca pela pacificação através de diálogos foi um dos principais objetivos da missão.

\section{CONSIDERAÇÕES FINAIS}

A partir da análise desenvolvida neste artigo é possível destacarmos algumas características com relação à transição entre a Organização da Unidade Africana (OUA) e a União Africana (UA), à importância que a segurança regional ganhou nesta organização, principalmente no período pós-Guerra Fria e, por fim, ao êxito e às dificuldades por ela encontrados em sua atuação na pacificação do Burundi.

Primeiramente, mesmo havendo a convergência em pontos relacionados ao aumento da integração, da unidade, da solidariedade entre os Estados-membros e do respeito à soberania, integridade territorial e independência dos Estados africanos, tornou-se claro que os objetivos e a atuação da OUA e da UA eram distintos. Enquanto a OUA era marcada pelo predomínio do pan-africanismo e representava a resposta africana ao mundo bipolar, voltando-se ao rompimento com quaisquer formas de dominação herdadas do 
imperialismo europeu, a intensificação do processo de independência se tornava preponderante se comparada com as questões internas dos novos países. Convém observar que a UA pauta-se no direito de intervenção em situações relacionadas a crimes de guerra, genocídios e crimes contra a humanidade, demonstrando a priorização dos assuntos internos dos países e vendo-os como necessários para a pacificação do continente.

Em certa medida, a transformação da OUA em UA demonstrou que as demandas pela reforma da estrutura da OUA ocorreram sobretudo pela incapacidade desta em solucionar boa parte dos conflitos remanescentes no continente africano frutos dos processos de independência. Além disso, pode-se indicar que essa transformação, somada à incorporação de uma nova diretriz pautada no principio da não indiferença em detrimento da não intervenção, marcou o inicio da construção de uma nova Arquitetura Africana de Paz e Segurança (APSA, do inglês African Peace and Security Architecture), pautada nos princípios de intervenção legitima da união nos Estados membros, em situações de crime de guerra, genocídio e violação maciça de direitos humanos, etc.

Portanto, a busca em romper com a instabilidade política no Burundi foi importante uma vez que colocou à prova a capacidade de gerenciamento, de resolução de conflitos e preservação da paz no continente da recém-criada União Africana. Apesar das dificuldades encontradas no terreno pelos peacekeepers da UA na implementação do mandato, nomeadamente no programa de DDR dos ex-combatentes, é possível afirmar que o primeiro envolvimento da UA em missões de paz no continente foi extremamente positivo, na medida em que a AMIB cumpriu quase a totalidade do seu mandato e foi competente para criar as condições mínimas de segurança necessárias ao estabelecimento da missão de paz da ONU no país.

Em suma, é possível concluir que, apesar de ter enfrentado dificuldades, a AMIB colaborou para o avanço da capacidade da UA de prevenção e resolução de conflitos, tornando-se o modelo de peacekeeping para as futuras missões de manutenção de paz não só da UA, mas também nas REC's engajadas nos processos de estabilização das suas respectivas regiões. No entanto, embora 
representando o êxito da UA, vale ressaltar que a AMIB expôs um dos principais obstáculos desta organização no campo de paz e segurança, no caso, a carência de recursos e de um maior comprometimento dos Estados membros para agir como um provedor de paz e segurança no continente africano, fator este que se anteriormente simbolizou um dos pontos falhos da atuação da OUA na pacificação do continente, atualmente deve ser visto como um desafio a ser enfrentado pela UA.

\section{REFERÊNCIAS}

ADEBAJO, A. South Africa and Nigeria in Africa: an axis of virtue? In: ADEDEJI, A.; ADEBAJO, A.; LANDSBERG, C. South Africa in Africa: the post-apartheid era. Cape Town: University of KawaZulu-Natal Press, 2007. p. 213-235.

AFRICAN UNION. Protocol relating to the establishment of the peace and security council of the African Union. Durban, 2002. Disponível em: <http://www.africa-union.org/root/au/ organs/psc/Protocol_peace\%20and\%20security. pdf>. Acesso: 28 mar. 2014.

Constitutive Act of the African Union (CAAU). Lome, 2000. Disponível em: <http://www.au.int/en/sites/default/files/ ConstitutiveAct_EN.pdf>. Acesso em: 10 mar. 2014.

Organization of African Unity Charter. Addis Ababa, 1963. Disponível em: <http://www.au.int/en/sites/default/files/ OAU_Charter_1963_0.pdf>. Acesso em: 10 mar. 2014.

AGOAGYE, F. The African mission in Burundi: lessons learned from the First African Union Peacekeeping Operation. Pretoria: Institute for Security Studies, 2004.

AKOKPARI, J. K. Post-Cold War International Relations and foreign policies in Africa. New Issues and New Challenges. African Journal of International Affairs,Dakar, v. 4, n. 1-2, p.34-55, 2001.

BEKOE, D. A. Implementing peace agreements: lessons from Mozambique, Angola, and Liberia. New York: Palgrave Macmillan, 2008. 
BOSHOFF, H.; VREY, W.; RAUTENBACH, G. The Burundi peace process: from civil war to conditional peace. Pretoria: Institute for Security Studies, 2010. (Monograph, 171). Disponível em: <https:// www.issafrica.org/uploads/Mono171.pdf>.

BOUTROS-GHALI, B. An Agenda for the peace: preventive diplomacy, peacemaking and peace-keeping. New York: Security Council, 1992.

CHANAIWA, D. A África Austral. In: MAZRUI, A. A.; WONDJI, C. (Orgs.). História geral da África - VIII: África desde 1935. Brasília: UNESCO, 2010. p. 295-334.

CHANAIWA, D.; KODJO, E. Pan-africanismo e libertação. In: MAZRUI, A. A.; WONDJI, C. (Orgs.). História geral da África VIII: África desde 1935. Brasília: UNESCO, 2010. p. 897-924.

CHINWEIZU, A. África e os países capitalistas. In: MAZRUI, Ali A.; WONDJI, C. (Orgs.). História geral da África - VIII: África desde 1935. Brasília: UNESCO, 2010; p. 927-963.

DENG, F. M.; ZARTMAN, I. W. A strategic vision for Africa: the kampala movement. Washington: Brookings Institution Press, 2002.

DORN, A. W.; PAUK, R. O capacete azul e a folha de bordo: as contribuições de Canadá para as operações de paz da ONU. In: KENKEL, K. M.; MORAES, R. F. (Orgs.). O Brasil e as operações de paz em um mundo globalizado: entre a tradição e inovação. Brasília: IPEA, 2012. p. 119-158.

ESCOSTEGUY, P. C. A nova arquitetura africana de paz e segurança: implicações para o multilateralismo e as relações do Brasil com a África. Brasília: FUNAG, 2011.

FUNKE, N.; NSOULI, S. M. The NEPAD: opportunities and challenges. Washington, DC: International Monetary Fund, 2003.

FRANCIS, D. Uniting Africa: building a regional peace and security systems. Hampshire: Ashgate Publishing Limited, 2006.

GODOI, T. B. Aspectos multidimensionais das missões de paz da ONU e MINUSTAH. Brasília: UNB, 2010.

HOBSBAWM, E. A era dos extremos (1914-1991): o breve século XX. São Paulo: Companhia das Letras, 1995. 
INTERNATIONAL CRISIS GROUP. Burundi: from electoral boycott to political impasse. Nairobi, 2011.

KENNEDY, P. Ascensão e queda das grandes potências. Rio de Janeiro: Campus, 1989.

KENT, V.; MALAN, M. Decisions, decisions, South Africa's foray into regional peace operations. Pretoria: Insitute for Security Studies, 2003.

ORGANISATION OF AFRICAN UNITY. Lagos plan of action for the economic development of Africa 1980-2000. Geneva, 1981. Dísponível em: <http://www.ilo.org/public/libdoc/ ilo/1981/81B09_473_engl.pdf>. Acesso em: 22 mar. 2014.

MINGST, K. Princípios das relações internacionais. Rio de Janeiro: Elsevier, 2009.

MITI. K. South Africa and Conflict Resolution in Africa: from Mandela to Zuma. Southern African Peace and Security Studies, v. 1, n. 1, p. 26-42, 2012.

MURITHI. T. The African Union's evolving role in peace operations: the African Union Mission in Burundi, the African Union Mission in Sudan and the African Union Mission in Somalia. African Security Review, v. 17, n. 1, p.70-82, 2008.

NHLAPO, W. Peacebuilding in Burundi. In: CCR/FES SEMINAR ON AFRICAN PERSPECTIVES ON THE UN PEACEBUILDING COMMISSION, 3-4 Aug. 2006 Maputo. Annals... Maputo: CCR/ FES, 2006. (Paper presented).

PAPAGIANNI, K. Power-sharing: a conflict resolution tool? Oslo: Centre for Humanitarian Dialogue, 2009.

PEEN RODT, A. The African Mission in Burundi: the successful management of violent ethno-political conflict? London: Exeter Centre for Ethno-Political Studies, May 2011. n. 10.

SANTOS, L. I. V. G. A arquitetura de paz e segurança africana. Brasília: Fundação Alexandre de Gusmão, 2011.

SECURITY COUNCIL. Resolution 1545. New York, 21 may 2004. Disponível em: <http://www.un.org/en/ga/search/view_doc. asp?symbol=S/RES/1545(2004)>. Acesso em: 23 mar. 2014. 
SOUTHALL, R. A long prelude to peace: South African involvement in ending Burundi's war. In: SOUTHALL. Roger (Org.) South Africa's role in conflict resolution and peacemaking in Africa. Cape Town: Ed. HSRC Press, 2006. p. 105-135.

Between competing paradigms: post-colonial legitimacy in Lesotho. In: MELBER, Hanning. Limits to liberation in Southern Africa: the unfinished business of democratic consolidation. Cape Town: HSRC Press, 2003. p. 115-133.

SVENSSON, E. The African Mission in Burundi: lessons learned from the African Union's first peace operation. Stockholm: FOI Swedish Defence Research Agency, 2008.

TIEKU, T. Explainig the clash and the accommodation of interests of major actors in the creation of the African Union. African Affairs, Oxford, v. 103, p. 249-267, 2004.

UNITED NATIONS. African Union/United Nations Hybrid operition in Darfur. [S.l.], 1992. Disponível em: <http://www.un.org/en/ peacekeeping/missions/unamid/index. shtml>. Acesso em: 12 fev. 2014.

VISENTINI, P. F. Os países africanos: diversidade de um Continente. Porto Alegre: Leitura XXI, 2012. p. 129-132.

A África na política internacional: o Sistema Interafricano e sua inserção mundial. Curitiba: Juruá, 2010.

WILliAMS, P. D. War and conflict in Africa. Cambridge: Polity Press, 2011. 